\title{
Analysis of Rigid Body Dynamic Excavator Crane Arm for Safety use in Mining and Infrastructure Industries
} using Ansys 16.2

\author{
Sumar Hadi Suryo \\ Diponegoro University, Engineering Faculty, Mechanical Engineering Department, Indonesia
}

\begin{abstract}
Excavators are one of the heavy equipment that is often used in the mining industry and infrastructure that can do work such as lifting the ground, digging and lifting other heavy objects using its bucket of teeth, making a quarry and moving objects into the tub. Excavators are widely utilized in the mining industry and infrastructure. In this research, it contains the design and analysis of the product of the crane arm excavator which has the form of adoption of catterpillar excavator. Test process conducted using software simulation Ansys 16.2 with Rigid Dynamic project, which is a total deformation test that occurs in crane arm excavator. At the time of analysis is given a joint load on four components that relate one rotation and four others move the rotation. In the components that are rotated rotation is given the limit $\mathbf{- 3 0 0}$, in the Translansi section is given a boundary $\mathbf{- 7 0} \mathbf{~ m m}$ upper, $\mathbf{- 8 0} \mathbf{~ m m}$ lower and-100 $\mathbf{~ m m}$ in the central part of the crane arm excavator model. A maximum deformation of $982.17 \mathrm{~mm}$ is generated and the minimum value generated in the test is 0 mm.
\end{abstract}

Keywords: Crane Arm Excavator, Rigid Dynamic, Total Deformation.

\section{INTRODUCTION}

Indonesia is a country that is rich in natural resources from Sabang to Merauke on every side of Indonesia, the abundant wealth of natural resources is above and below the Earth Indonesia. The natural resources can then be in the realization of the sila to five of the Pancasila, namely welfare in the people of Indonesia. Basically, development in the field of mining and energy is an effort from the process of the development of mineral and energy resources owned by the Indonesian state and the Indonesian people for use properly and on the target on the side also pay attention to the security of the workers. Indonesia's tropical rainforest is where flora and fauna grow, forming a life of almost dynamic balance (Heryanto, 2012). Supporting conditions, Indonesia is one of the largest commodity-mining countries in the world. In 2020 the government targeted 155 million tons of its production targets of 550 million tons of coal production (Kompas, Adi 19-01-2020).

Infrastructure acts as a vital part of the driving growth of the country and society in general, and infrastructure is seen as a locomotive of national and regional development. The infrastructure project in Indonesia has recently been one of the visions of the Indonesian government, as an example of a toll road that has been connected from Jakarta to the tip of Java Island. Some areas that are also the center of government attention is the tourist areas that are located from the island of Sumatra to Papua including Labuan Bajo, Borobudur, Circuit Mandalika and others (Hadimuljono, 2020). A wide variety of functions that Government should do such as the law enforcement, but development is also part of the main function that must be done by the Government to launch all the economic progress of the community aimed at lowering the level of poverty. Quite a lot and the magnitude of the development role, in a study conducted in the United States (Aschauer, 1989 and Munnel, 1990) showed the return level of investment in the field of infrastructure very quickly reached $60 \%$ (Suyono Dikun, 2003). When viewed on the concept of development, it is part of the utilization of natural resources, relationships and education for the community. From this point of view, development is considered a technique of utilization of resources that exist is in the public hands, such as natural resources, energy resources, sources of funds and human resources.

The level of growth that differs from each region raises new problems in the field of infrastructure that causes the difference of service that exists in each region. Therefore, the infrastructure needed to be developed and expected by the development is able to provide a description of infrastructure needs (Ariastita and Prasista, 2013). Mining and infrastructure is an industry that has a considerable role in Indonesia, the development of infrastructure that is done by governments and mining world also increasingly shows positive value from year to year. The positive results of these two industries make the need for supporting tools also greater, as a result the manufacturing industry also gets a positive scan of it. Tools of supporting the mining industry and infrastructure as a magnet 
ISSN (online): 2581-3048

for the manufacturing industry, because of its high needs and demand that is almost scattered throughout the territory of Indonesia. Tools of supporting mining industry and infrastructure one of them is heavy equipment.

Machines are tools or equipment that spring used in conducting industrial projects ranging from small to large scale. The positive value in using heavy equipment is that the project is faster to complete because it is able to do a great job when compared with the array of tools that require more workers but the time needed is also longer. It is not necessary to take a long time to finish the industrial project. Heavy equipment used in construction projects are trucks, heavy dump truck, digging equipment (excavators), bulldozers, cranes, soil compactors, for example compactors and roller, etc.. The crane arm design is required to have the right dynamics mathematically so that there is no work accident on the mining industry project and infrastructure. In general, the objects processed by excavators from both industries are the same, namely land. From the existing design now have parts that can move the revolution and the parts that can move the translation is the hydraulic part.

Based on the above problem, can be done analysis on the design of Crane arm excavator which first created 3D model in Solid works 2019 software with attention to the value of the revolution angle in the moving part of rotation and the displacement in the part that is moving translation with the purpose of excavator can work maximally and securely. This analysis of Crane arm excavator is expected to meet the demands of the mining and infrastructure industry and can be further developed to be mass-produced.

\section{CONCEPT ANALYSIS}

Heavy equipment is an object used to perform various project works with humans as its operator. Heavy equipment has become an important part of a job, for example construction projects, if the condition of the soil to be constructed a contract when the heavy equipment such as excavators do not exist then the construction of the project is very long, in addition to the mining industry, infrastructure. None other than every use of the tools is to make the work more efficient, effective and timely.

Excavator is a heavy lat that has a wide range of functions because it can do various jobs such as increasing the depth of land, making a quarry, moving the mines into the dump truck. The crane arm excavator design to be made has a typical like design. In the process of designing, taking into account the grounding parts with the body, moving parts of the revolution and the moving parts.
https://doi.org/10.47001/IRJIET/2020.407004

Here is a flowchart showing the teeth bucket of the design.

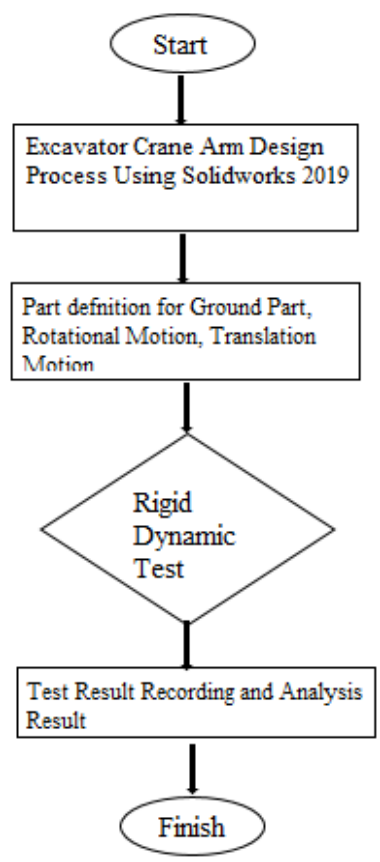

Figure 1: Flow Chart of Tool design stages

\subsection{Product Design}

The product that will be in the analysis, is the form of crane arm excavator that many in production. Researchers concluded the conclusion of the analysis results of the total deformation to be compared to the requirements of total deformation allowed. The design of the researcher can be seen in Figure 2, where the crane arm excavator design is made as in general with the part that moves in translation using hydraulic 4 parts, rotating parts of each section with connectors and grounding shafts that form a slab.

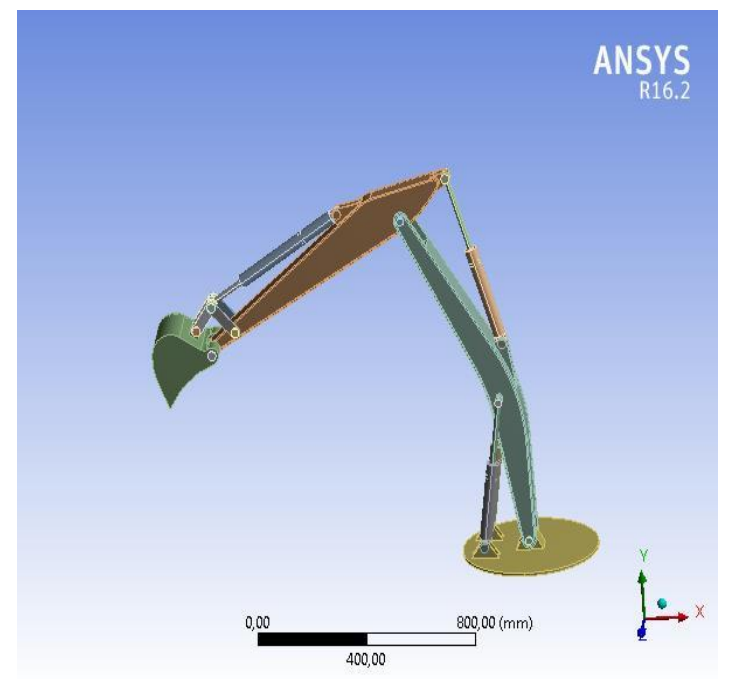

Figure 2: Design Crane Arm Excavator 
ISSN (online): 2581-3048

\subsection{Analysis Phase}

At the stage of analysis using Ansys software there are several stages. The stage sequence is performed as follows; (1) Determine the type of analysis performed, (2) Determine engineering data, (3) Import geometry, (4) Open Mechanical tab Ansys (5) Solving Problem.

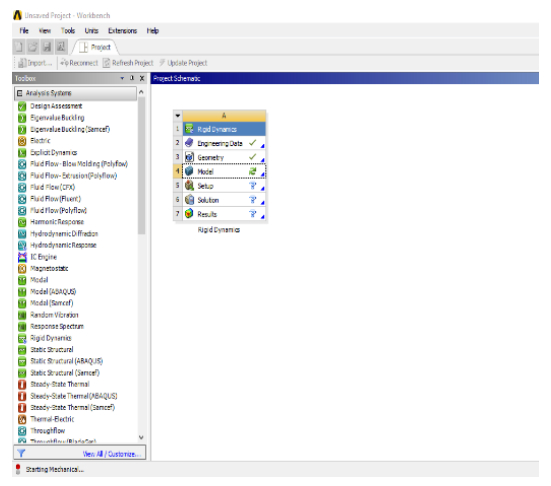

Figure 3: Project lists that can be done in Ansys

\subsubsection{Specifying the Type of Analysis to be performed}

On Ansys software There are several analysis options performed such as; Eigen Buckling, CFDS, Fluid Flow CFX, Hydrodynamic diffraction State Thermal, Structural analysis and others. Where each tools has different functions according to the analysis purpose we want. In Crane arm excavator analysis using Rigid Dynamic analysis option.

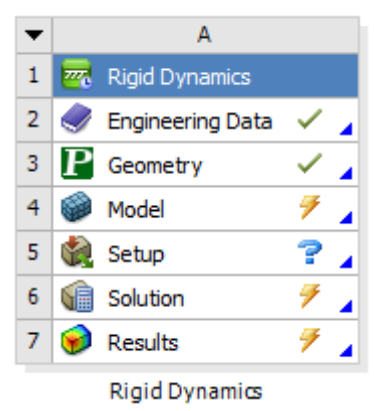

Figure 4: Bar Rigid Dynamic

\subsubsection{Specifying Engineering Data}

At this stage, the material selection is used for the crane arm excavator. The selected Material is structural steel with the data as shown in Figure 5.

\begin{tabular}{|c|c|}
\hline \multicolumn{2}{|c|}{ Structural Steel > Constants } \\
\hline Density & $7,85 \mathrm{e}-006 \mathrm{~kg} \mathrm{~mm}^{\wedge}-3$ \\
\hline Coefficient of Thermal Expansion & $1,2 \mathrm{e}-005 \mathrm{C}^{\mathrm{n}-1}$ \\
\hline Specific Heat & $4,34 \mathrm{e}+005 \mathrm{~mJ} \mathrm{~kg} \mathrm{~kg}^{\wedge}-1 \mathrm{C}^{\wedge}-1$ \\
\hline Thermal Conductivity & 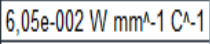 \\
\hline Resistivity & 1,7e-004 ohm mm \\
\hline
\end{tabular}

Figure 5: Data Material

\subsubsection{Import Geometry}

The stage of Import geometry is the process of transferring 3D models that have been designed in the solid work to Ansys software. This stage aims to make the analysis form appear in the Mechanical Tab Ansys to be the model to be analyzed.

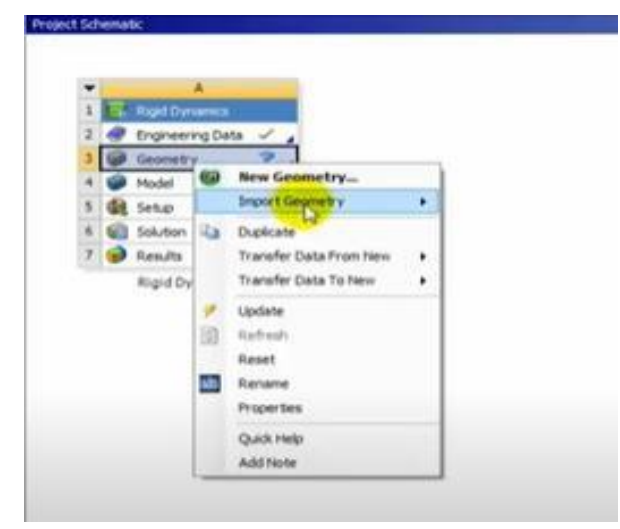

Figure 6: Tools Import Geometry

\subsubsection{Tab Mechanical Ansys}

In the Mechanical Ansys tab there are several processes before doing solving problems including determining the coordinates that will be in the analysis, determining the connection between parts, meshing, load-bearing and problem solving.

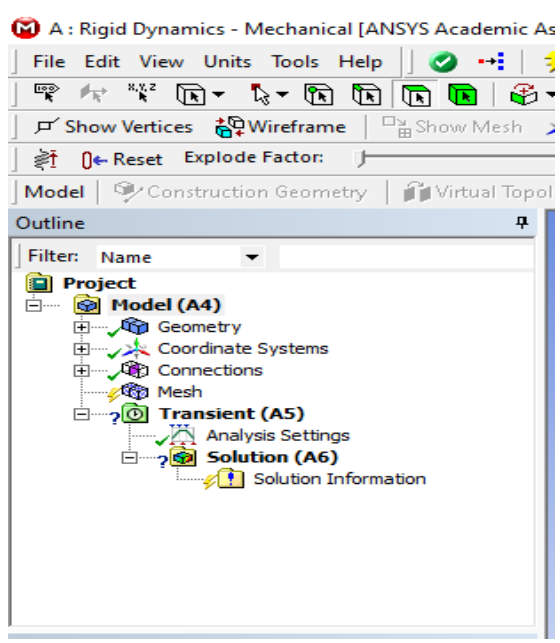

Figure 7: Tab Mechanical Ansys

\section{DISCUSSION}

Analysis on crane arm excavator channeled using ANSYS 16.2. Before performing solving problem (problem solving) is done by determining connection between parts. The first part of the relationship is Body-Ground which is the location determination of the body crane arm excavator on the excavator body. 


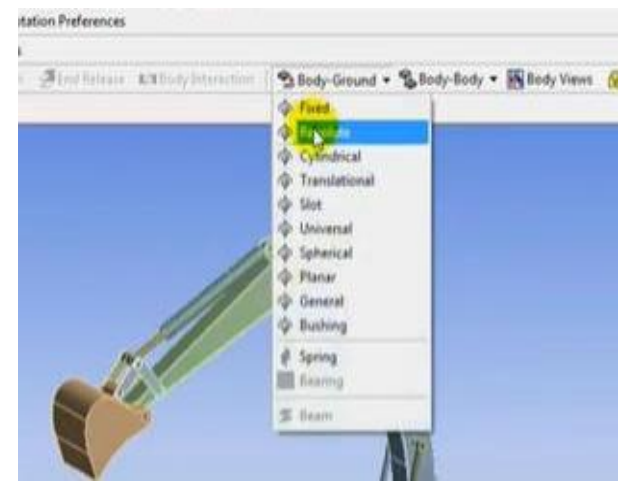

Figure 8: Body-Ground fixing

Then the relationship is determined between moving parts, at this stage the part that has the nature of rotation motion there are twenty-six locations according to the design that has been made.

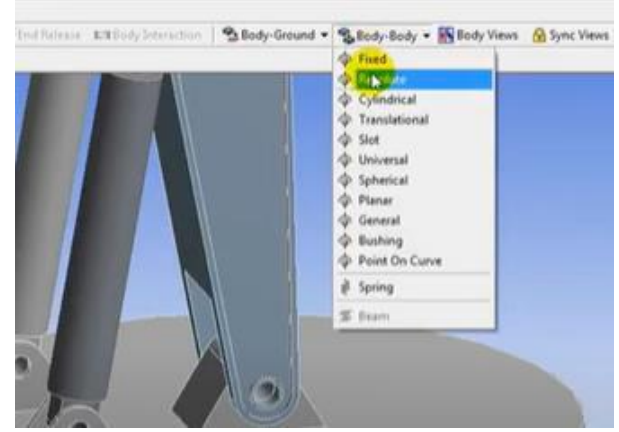

Figure 9: Connection Revolute

The next step is to determine the part that is moving. In the crane arm excavator design, there are four locations that move precisely in the hydraulic crane arm.

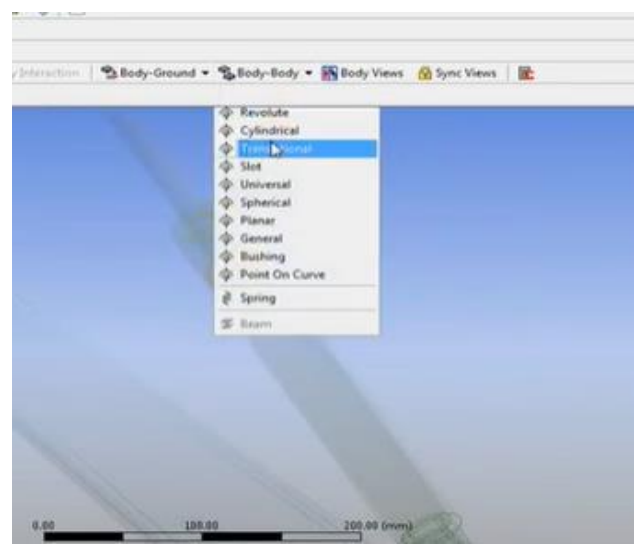

Figure 10: Connection Translational

After determining the relationship between parts, the meshing process is done by tapping the Generate Mesh icon in the Ansys Mechanical Tool Bar. In this process Mesh will be known how good and thorough geometry or model that we have worked on, if there is an error on the model then there
Volume 4, Issue 7, pp 20-25, July-2020

https://doi.org/10.47001/IRJIET/2020.407004

will arise the yours for the design optimization in advance so as to be done generate Mesh.

\subsection{Loading Test}

The load is done using the Ansys Mechanical Tool Bar as Loads, then by selecting the Joint load option. In this test researchers determine the 5 parts that will be given a burden ie; Body-Ground between the crane arm with the body of an excavator and on each hydraulic component that moves in translation of four dots. For Body-Ground There is rotation motion and is limited to displacement nya-300. Then give a displacement limitation on the components that are translation. The limit varies depending on the relationship between components. In the hydraulic components below two were given a limit of $-80 \mathrm{~mm}$. Then the hydraulic components in the middle were given a displacement limitation of $-100 \mathrm{~mm}$. The hydraulic compensator that is closest to the teeth excavator bucket is given a displacement limit of $-70 \mathrm{~mm}$.

In Figure 11, a transient joint load is displayed given as many as five locations.

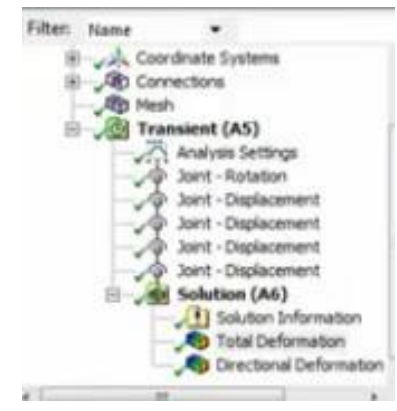

Figure 11: Transient Joint Load

\subsection{Solving and Results}

After the entire joint load at the specified location testers derive then done Solution Total Deformation so that the solution we want appears on the results of animation. In Figure 12 below shows how to perform solving on the analysis.

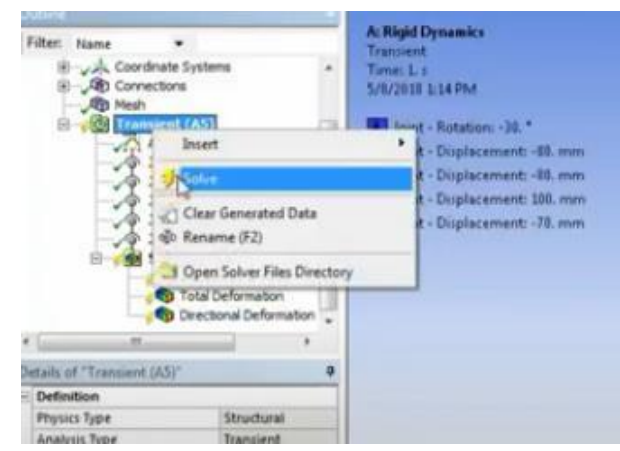

Figure 12: Solve Mathematic Model 
ISSN (online): 2581-3048

Volume 4, Issue 7, pp 20-25, July-2020 https://doi.org/10.47001/IRJIET/2020.407004

Then it will take place running process in a certain time until the results arise and animation testing that we do. In Figure 13 is shown the total deformation results on the tests already performed.

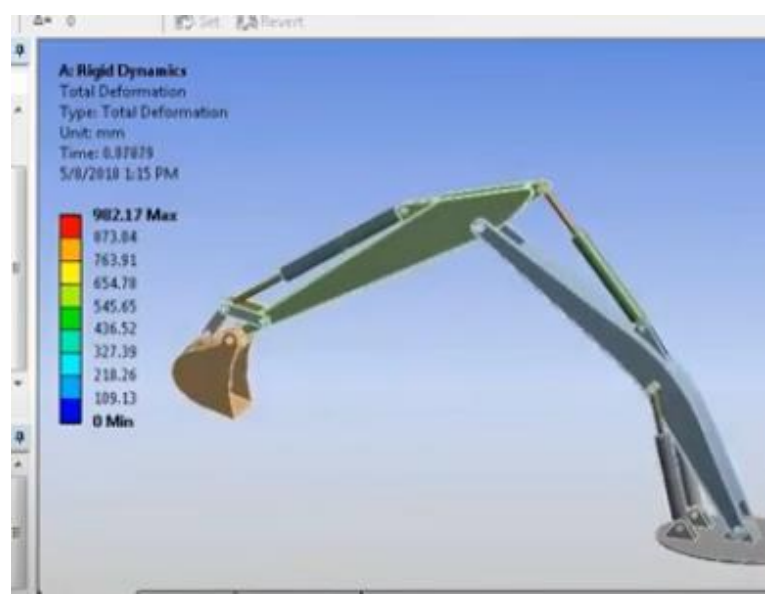

Figure 13: Total Deformation Result

The results obtained in the tests are tabulated in the Table 1 below.

Table 1: Total Deformation Results

\begin{tabular}{|c|c|}
\hline $\begin{array}{c}\text { Joint Load } \\
\text { Displacement }\end{array}$ & Deformation Total (mm) \\
\hline Min & 0 \\
\hline & 109,13 \\
\hline & 218,26 \\
\hline & 327,39 \\
\hline & 436,52 \\
\hline & 545,65 \\
\hline Max & 654,70 \\
\hline
\end{tabular}

\section{CONCLUSION}

Based on the design and results of the Rigid Dynamic analysis conducted against the crane arm excavator with the provision of a joint load resulted in several conclusions:

1. The minimum or least small value of the deformation is $0 \mathrm{~mm}$ where the excavator condition has not been operating so there is no burden causing the deformation on the crane arm excavator.
2. Maximum allowable value is $982.17 \mathrm{~mm}$ in order to avoid a working accident.

3. The increase starting from the start is given a load approaching the linear line with a increase of approximately $100 \mathrm{~mm}$.

\subsection{Advice}

The analysis of this product is made with the main objective to pay attention to the safety of industrial processes conducted using excavators. From it can still be redesigned to get a higher total deformation value and for better safety.

\section{REFERENCES}

[1] Arsić, M., Bošnjak, S., Zrnić, N., Sedmak, A., Gnjatović, N. 2011, "Bucket wheel failure is caused by residual stress on the welded joint", Failure Analysis Techniques, 18, 700-712.

[2] Arsi, M., Bošnjak, S., Gnjatović, N., Sedmak, SA, Arsić, D., Savić, Z. 2018, "Determination of Fatigue Life Structure remaining in Welded Wheel Excavators through the Use of Fracture Mechanics", Procedia's Structural Integrity, 13, 79-84.

[3] Bošnjak, S., Arsić, M., Zrnić, N., Rakin, M., Pantelić, M. 2011, "Bucket wheel excavators: Assessment of the integrity of boom-tie boom-rod boom wheels", Engineering Failure Analysis, 18, 212-222.

[4] Lazarević, Ž., Aranđelović, I., Kirin, S. 2015, "Analysis of random mechanical failure of bucket wheel excavators", Structural Integrity and Life, 15.3, 143-146.

[5] Danicic, D., Sedmak, S., Ignjatovic, D., Mitrovic, S. 2014, "Bucket Wheel Excavator Damage by Fatigue Fractures - Case Study", Procedia Sciences, 3, 17231728.

[6] Bošnjak, S., Arsić, M., Savićević, S., Milojević, G., Arsić, D. 2016, "Analysis of pulley fracture from the hoist boom wheel hoist system", Eksploatacja $i$ Niezawodnosc - Maintenance and Reliability, 18.2, 155-163.

[7] Bošnjak, S., Arsić, M., Gnjatović, N., Milenović, I., Arsić, D. 2018, "Bucket bucket excavator failures", Engineering Failure Analysis, 84, 247-261.

[8] Djurdjević, Dj., Maneski, T., Milosevic-Mitić, V., Andjelić, N., Ignjatović, D. 2018, "Failure of investigation and repair of gaps in booms from ERS 1250 Gacko bucket wheel excavators", Engineering Failure Analysis, 92, 301-316. 


\section{Citation of this Article:}

Sumar Hadi Suryo, "Analysis of Rigid Body Dynamic Excavator Crane Arm for Safety use in Mining and Infrastructure Industries using Ansys 16.2" Published in International Research Journal of Innovations in Engineering and Technology IRJIET, Volume 4, Issue 7, pp 20-25, July 2020. https://doi.org/10.47001/IRJIET/2020.407004 